\title{
Observation of the Liquid Water Content of Melting Snowflakes with a New Instrument
}

\author{
By Yoshio Sasyo, Taro Mori, Osamu Onozaki
}

and

\author{
Takashi Saito
}

Research and Development Division of Suga Weathering Test Instrument Co., Ltd. (Manuscript received 7 November 1989, in revised form 5 December 1990)

\begin{abstract}
In order to measure the liquid water content of a melting snowflake, a new automatic instrument based on a filter paper technique has been developed and used for field observation of sleet.

Analysis of the observational data indicated that the relationship between the liquid water content $W$ and the mass of the snowflake $m(\mathrm{mg})$ could be expressed as $W=\beta m^{-\alpha}$. $\alpha$ and $\beta$ range from 0.27 to 0.95 ( 0.53 in an average) and 0.07 to 0.51 ( 0.25 in an average), respectively.

A simple model for the melting of snowflakes showed that $\alpha$ was a parameter depending on the fall velocity of the snowflake alone and parameter $\beta$ depends on the quantity of heat transferred from ambient air to the snowflake and the density of the ice skeleton in the melting snowflake as well as the fall velocity.
\end{abstract}

\section{Introduction}

The measurement of the liquid water content of snowflakes is important for studies of sleet formation in the melting layer.

However, the only technique for measuring the liquid water content available has been "a filter paper technique" developed by Nakamura (1960).

The technique is very simple and convenient but it has some defects. For example, the filter paper technique is unsuitable for simultaneous measurement of many snowflakes and also the melting of collected snowflakes will probably proceed while taking the measurement. We have designed a new automatic instrument for measuring the liquid water content of snowflakes to improve these defects. In this paper, we will present a detailed description of the new instrument. Some field observations using the new instrument were made and the results were analyzed.

\section{Instrument and procedure}

\subsection{The filter paper technique}

A filter paper dusted with fine water-soluble dye particles has been used for measurement of the mass of rain drops and snowflakes. Nakamura (1960) applied the filter paper technique to the measurement of liquid water content of snowflakes.
His filter paper technique is as follows;

falling snowflakes are collected on the filter paper dusted with water-soluble dye particles. Liquid water in the melting snowflake is quickly absorbed by the filter paper and the wet area is stained by dissolved dye. The perimeter of the stain is outlined in pencil. Then, the ice remaining on the paper is melted by warming the paper. The stain becomes larger by the addition of water produced by melting. The area of the inner and outer stain are converted into the mass with the aid of a calibrated scale. Then, the liquid water content is obtained from a ratio of the mass corresponding to inner area to that of the outer one.

A roll of qualitative filter paper No. 1 (Toyo Roshi Kaisha Ltd.) was employed for the new instrument. The filter paper is dusted with aniline-blue powder by soaking it in the gasoline in which aniline-blue powder is suspended.

The calibration of the filter paper is carried out for water drops of known mass generated from a micro injector. The area of the stains produced by water drops with a fixed mass on the filter paper are measured by using an image analyzer. The relationship between the mass of water drop and the area of stain is obtained as follows

$$
m=0.063 A
$$




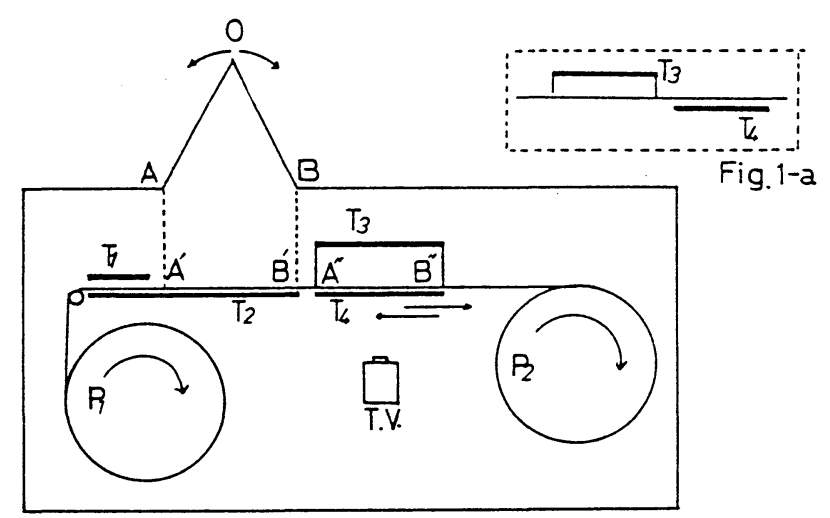

Fig. 1. The schematic diagram of the instrument. $\mathrm{P}_{1}, \mathrm{P}_{2}$ : Reels for filter paper tape. $\mathrm{T}_{1}, \mathrm{~T}_{2}$ : Metal plates kept at $0^{\circ} \mathrm{C}$. A" $\mathrm{T}_{3} \mathrm{~B} \mathrm{~T}_{4}$ ": Thermally insulated box. $\mathrm{T}_{4}$ : Movable bottom of the thermally insulated box. T. V: video camera. AOB: Shutter.

where $\mathrm{A}\left(\mathrm{mm}^{2}\right)$ is the average area of the stains produced by drops of known mass $m(\mathrm{mg})$. Equation (1) can be applied to masses between 0.1 and $10 \mathrm{mg}$.

The error of the filter paper technique was of the order of $\pm 0.05 \mathrm{mg}$ for masses under $1.0 \mathrm{mg}$ and of the order of $\pm 0.5 \mathrm{mg}$ for masses 1.0 to $10 \mathrm{mg}$ (Sasyo et al., 1990).

The liquid water content obtained from the filter paper technique must contain some errors. However, the errors will not be a serious problem, because the errors compensate each other when taking average of the liquid water content.

\subsection{Description of the new instrument}

The arrangement of the instrument is schematically shown in Fig. 1. As shown in the figure, the roll of filter paper tape $(15 \mathrm{~cm} \times 50 \mathrm{~m})$ on a supply reel $P_{1}$ is fed to a take-up reel $P_{2}$ through the gap between two metal plates $\left(\mathrm{T}_{1}, \mathrm{~T}_{2}\right)$ and the thermally insulated box (A", $\mathrm{T}_{3}, \mathrm{~B}$ ", $\left.\mathrm{T}_{4}\right)$. The metal plates $\mathrm{T}_{1}$ and $\mathrm{T}_{2}$ are placed parallel about $0.3 \mathrm{~cm}$ apart and kept at $0^{\circ} \mathrm{C}$ by a thermoelectric module in order to keep the filter paper between them at nearly $0^{\circ} \mathrm{C}$. The thermally insulated box of $20 \times 20 \mathrm{~cm}^{2}$ in cross-section and $7 \mathrm{~cm}$ in depth is made of the metal plates and the sides are covered with thermal insulator boards. The bottom plate $\mathrm{T}_{4}$ was made to slide away to make the bottom side of the tape visible for observation by a video camera. The temperature of the top and bottom metal plates $\mathrm{T}_{3}$ and $\mathrm{T}_{4}$ are controlled by the thermoelectric module. Small fans were provided to make the temperature distribution uniform in the box. A video camera is set facing upward, just under the box.

The whole instrument is placed inside a hut under an opening on the roof. The opening of the instrument is covered by a shutter, AOB, placed directly below the opening on the roof.
As snowfall begins, snowflakes enter into the hut through the opening on the roof. The shutter AOB is opened for a set time interval to collect snowflakes on a segment of the tape A' B' whose temperature is kept at nearly $0^{\circ} \mathrm{C}$. Then the shutter is closed and the snowflakes collected at the segment A' B' are transferred to A" B" in the thermally insulated box by advancing the filter paper. The temperature is kept at $0^{\circ} \mathrm{C}$ in order to prevent further melting of the collected snowflakes. The snowflakes are kept in the box for two minutes. Any liquid water in the snowflakes is completely absorbed by the filter paper and leaves stains on it.

After two minutes, the bottom plate $\mathrm{T}_{4}$ slides as shown in Fig. 1a to expose the bottom side of the stain on the filter paper. The images of the stain are transferred to an image analyzer through a video camera. Let us call the image A-image hereafter. The image analyzer converts individual stains of Aimage into mass through Eq. (1). Then the plate $\mathrm{T}_{4}$ is returned to the bottom of the thermally insulated box.

Next, the box is heated by the thermoelectric modules on plate $\mathrm{T}_{3}$ and $\mathrm{T}_{4}$ and kept for two minutes at nearly $8^{\circ} \mathrm{C}$ in order to melt the remaining ice. The stains become larger by the addition of water produced by melting. The image of enlarged stains are again transmitted to the image analyzer and converted into the mass in the same way as for the case of A-image. Let us call the image of the spreaded stains B-image. The image analyzer identifies the stains of the A- and B-images and deduces the liquid water content of individual snowflakes from the ratio of the mass of $\mathrm{A}$-image to that of $\mathrm{B}$-image. The thermally insulated box is cooled again to $0^{\circ} \mathrm{C}$ and readied for the next measurement. One cycle of measurement is completed in 10 to 15 minutes depending on the number of the items of measurement.

\subsection{Results}

The snowfall observations were carried out from December 1987 to March 1988 at Hiratsuka, Kanagawa prefecture and Ishiuchi, Niigata prefecture, Japan. In this period, four sleet events were observed at Hiratsuka (5 and 6, Jan. 1988; 25 and 27 Feb. 1988), and two sleet events at Ishiuchi (17 Dec. 1987; 5 Mar. 1988). The four sleets at Hiratsuka were accompanied by cyclones traveling over the Pacific Ocean. On the other hand, the sleet of $17 \mathrm{Dec}$. 1987 at Ishiuchi was accompanied by an outbreak of monsoon and that of 5 Mar. 1988 at Ishiuchi was accompanied by a trough behind a moving anticyclone. The meteorological data for these sleets are listed in Table 1.

\subsubsection{Dispersion of liquid water content of melting snowflakes}

The data were classified in intervals of $0.1 \mathrm{mg}$ 


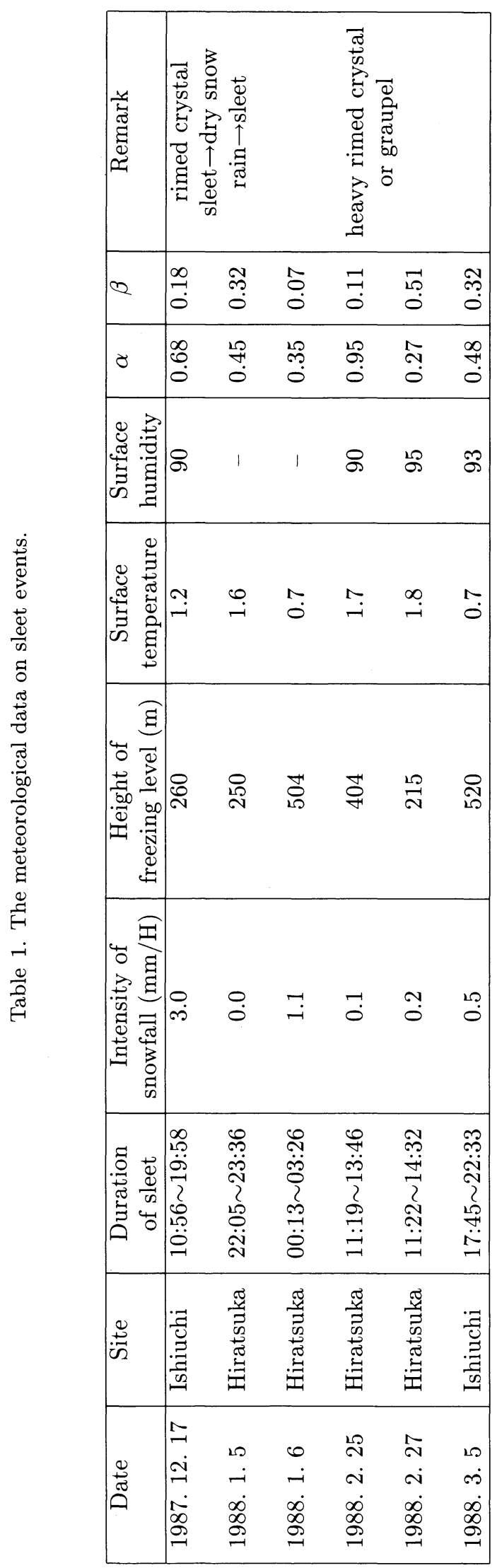




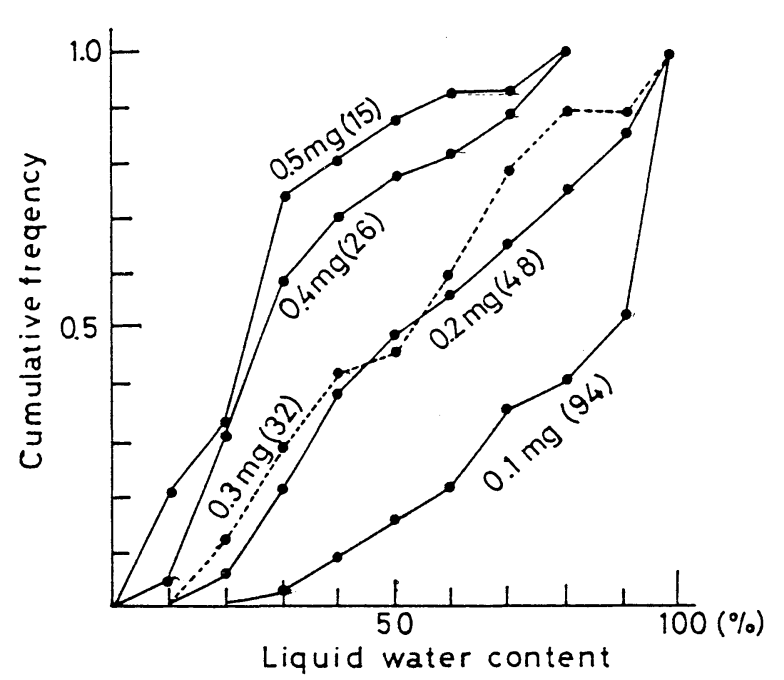

Fig. 2. An example of cumulative frequency distributions of water content for five groups of snowflake with mass ranging from $0.1 \mathrm{mg}$ to $0.5 \mathrm{mg}$ (17 Dec. 1987). The numbers in parenthesis are the number of utilized data.

mass for snowflakes $m$. The cumulative frequency distributions of the liquid water content of snowflakes were made for each mass group. Figure 2 shows some examples of the cumulative frequency distribution of the liquid water content of snowflakes for five groups $(m=0.1,0.2, \cdots, 0.5 \mathrm{mg})$. These data are ones of 17 Dec. 1987. The ordinate and abscissa are the cumulative frequency and the liquid water content of snowflakes, respectively. The mass and number of utilized data are shown by the curves. Figure 2 shows that snowflakes have a variety of liquid water contents regardless of the mass and the curves denoting the distribution increase in a zig-zag way with liquid water content. However, the trend of the curves changes from concave to convex as the mass increases. The fact suggests that the smaller the mass of snowflake, the larger the proportion of the snowflake having higher liquid water content in the group is, and vice versa. Consequently, we can generally say that the average liquid water content of a snowflake decreases with an increase in the mass.

We will discuss the relationship between the average liquid water content and the mass of snowflakes in the next section.

\subsubsection{Relationship between the average liquid water content of snowflakes $W$ and the mass $m$}

The average liquid water content of snowflakes $W$ is calculated for each group of snowflakes described above and plotted as a function of the mass of snowflake $m$ on a logarithmic scale. Figure 3 shows a $\log W$ vs. $\log m$ relationship. In Fig. 3, the ordinate and abscissa are the average liquid water content and the mass of snowflake expressed in mg, respectively.

The dates of measurements are 17 Dec. 1987 at Ishiuchi (Fig. 3a), 5 Jan. 1988 (Fig. 3b) and 6 Jan. 1988 (Fig. 3c) at Hiratsuka, 25 Feb. 1988 (Fig. 3d) and 27 Feb. 1988 (Fig. 3e) at Hiratsuka and 5 Mar. 1988 (Fig. 3f) at Ishiuchi. In the figure, the crosses are the raw value of single measurements. The crosses appear in the region where the number of data are small. As shown in Fig. 3, the $\log W$ vs. $\log m$ relationship can be approximated by a linear equation.

$$
\log W=-\alpha \log m+\log \beta
$$

where parameters $\alpha$ and $\beta$ are independent of the mass of snowflake. The parameter $\alpha$ determines the slope of the line and the value of $\beta$ equals the liquid water content of a snowflake with a mass of $1 \mathrm{mg}$. In Fig. 3, the best-fit lines for each snowfall were calculated by a linear regression method. The surface average temperature and humidity are also shown at the top right corners.

The values of $\alpha$ lies in the region of 0.27 to 0.95 ( 0.53 on average) and $\beta$ lies 0.07 to 0.51 ( 0.25 on average). For graupel (25 Feb. 1988 at Hiratsuka) the value of $\alpha$ is considerably larger and conversely $\beta$ very small.

\section{Theoretical treatment of the $W$ vs. $m$ re- lationship}

The relationship between $W$ and $m$ can be found by solving the equation that governs the melting of snowflake.

The thermal condition of melting snowflakes can be expressed as follows,

$$
-L_{f} d m_{i} / d t=H
$$

where $L_{f}$ is the latent heat of fusion of ice, $m_{i}$ the mass of the ice portion in the melting snowflake and $H$ the heat transfer rate from the ambient air to the snowflake.

Unfortunately, the expression for the heat transfer is not known except for particles having simple shape such as a sphere or a circular disk. We will adopt the following assumptions based on Matsuo and Sasyo (1981);

(1) The ice portion of snowflake is spherical and has a skeletal structure uncollapsible until the completion of melting. The assumption also means that the density of the ice skeletal structure $\rho$ is kept unchanged during the melting period.

(2) Melting takes place on a surface of the skeleton and the water produced by melting on the surface penetrates into the inside but does not make any contribution on the subsequent melting.

For simplicity, we add another assumptions:

(3) The liberation of latent heat for the evaporation, condensation and sublimation of water can be neglected. 


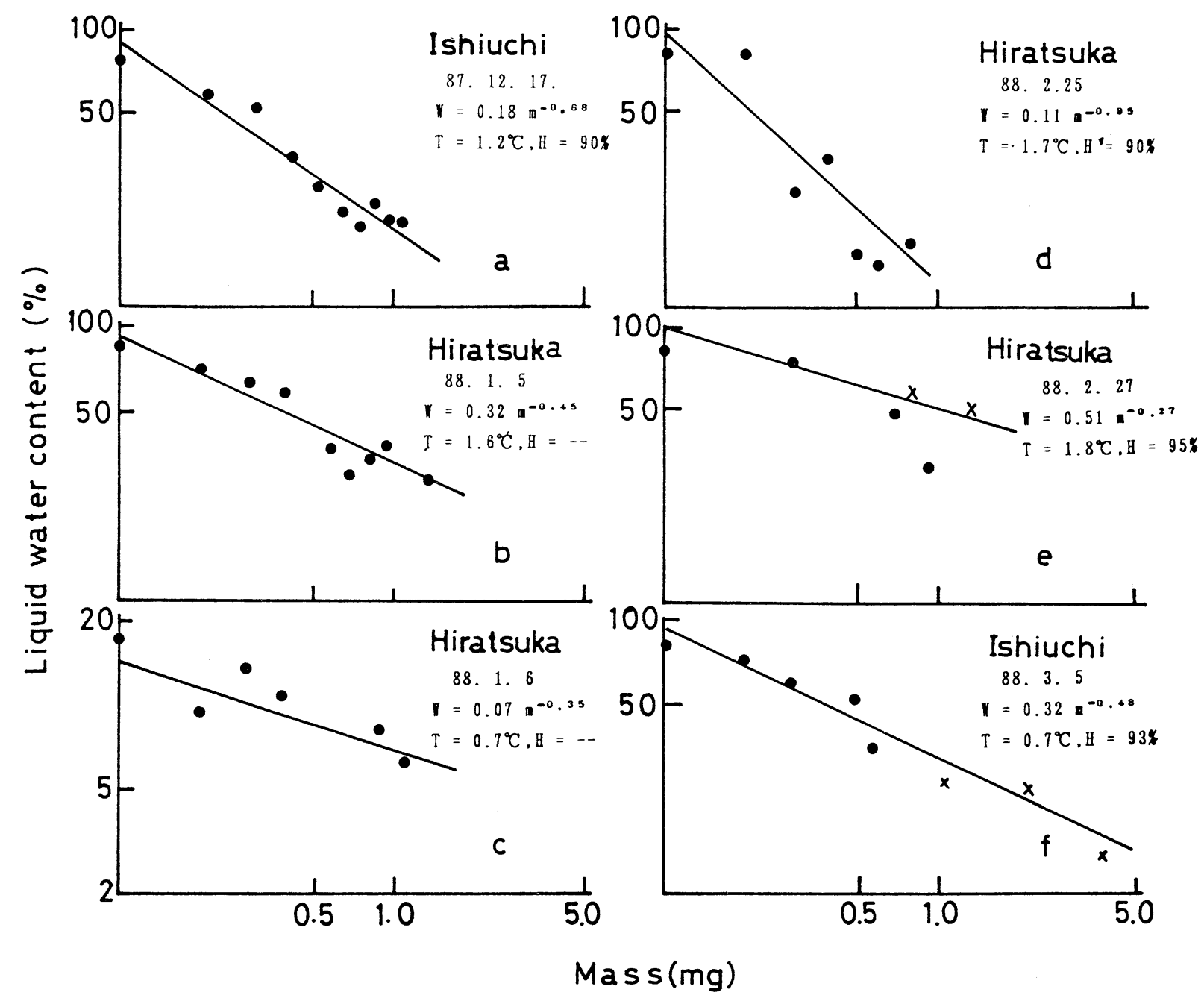

Fig. 3. The relationship between the liquid water content of a snowflake and its mass. Both scales of the vertical and horizontal axes are logarithmic. The solid circles show an average liquid water content in each mass range. The crosses are single measurements. The observation site, date, the equation of the best-fit lines, surface mean temperature and surface mean humidity are shown at top right corner in the corresponding graphs.

Under such assumptions, Eq. (3) can be expressed as follows,

$$
-L_{f} d m_{i} / d t=H=4 \pi R \cdot \phi \cdot K \cdot \Delta T
$$

where $R$ is the radius of the ice skeleton. $\phi$ the ventilation factor for heat diffusion. $K$ the thermal conductivity of air, and $\Delta T$ the temperature difference between the surface of the melting snowflake $\left(0^{\circ} \mathrm{C}\right)$ and the air temperature at a sufficient distance to be unaffected by the snowflake.

In Eq. (4), the ventilation factor $\phi$ was determined experimentally by Yuge (1960) to be of the following form

$$
\phi=1+0.275 \operatorname{Pr}^{\frac{1}{3}} \cdot \operatorname{Re}^{\frac{1}{2}}(10 \leq R e \leq 1800)
$$

where $\operatorname{Pr}$ and $R e$ are the Prandtl number $(\doteqdot 0.71)$ and Reynolds number, respectively. The Reynolds number of snowflakes is generally larger than 300 .
In this range of Reynolds number Eq. (5) can be approximated by

$$
\phi \doteq 0.24 \cdot R e^{\frac{1}{2}}
$$

Substituting Eq. (6) into Eq. (4), the following equation can be obtained

$$
-\left(d m_{i} / d z\right)(d z / d t)=0.96 \pi R \cdot R e^{\frac{1}{2}} \cdot K \cdot \Delta T(7)
$$

where $z$ is fall distance of snowflakes below freezing level and $d z / d t=V$ is the fall velocity of snowflake.

The radius of the ice skeleton $R$ and the Reynolds number $R e$ can respectively be expressed as follows

$$
\begin{aligned}
& R=\left[3 m_{i} /(4 \pi \rho)\right]^{\frac{1}{3}} \\
& R e=2 R V / \nu
\end{aligned}
$$

where $\nu$ is the Kinematic viscosity of the air and $\rho$ the density of the ice skeleton. The density is 
constant during the melting under the assumption (l).

Substituting Eqs. (8) and (9) into Eq. (7),

$$
-d m_{i} / d z=A \cdot V^{-\frac{1}{2}} \cdot m_{i}^{\frac{1}{2}} \cdot K \cdot \Delta T
$$

where

$$
A=\left(0.96 \pi / L_{f}\right) \cdot\left[(3 /(2 \pi \nu \rho)]^{\frac{1}{2}}\right.
$$

We use an approximate relationship between the fall velocity $V$ and the melted diameter $D$ (Langleben, 1958; et al.). i.e.

$$
\begin{aligned}
V & =k \cdot D^{n} \\
& =k \cdot\left[\left(6 / \pi \rho_{w}\right) \cdot m\right]^{\frac{n}{3}} .
\end{aligned}
$$

where $k$ and $n$ are parameters depending on the basic crystal types in the snowflake, the rimming and melting of the snowflakes and $\rho_{w}$ the density of liquid water. Assuming that the fall velocity of the snowflake is constant during the melting period, Eq. (10) can be solved to give the following solution.

$$
2\left(m^{\frac{1}{2}}-m_{i}^{\frac{1}{2}}\right)=A \cdot V^{-\frac{1}{2}} \cdot \int_{0}^{z_{0}} K \cdot \Delta T d z
$$

where the integral is carried out from the freezing level ( $z_{0}$ in height) to the ground ( 0 in height) related to melting.

The solution (13) can be rewritten by using the liquid water content $W=1-\left(m_{i} / m\right)$ in place of $\left(m_{i} / m\right)$ in following form

$$
2 m^{\frac{1}{2}}\left[1-(1-W)^{\frac{1}{2}}\right]=A \cdot V^{-\frac{1}{2}} \cdot \int_{0}^{z_{0}} K \cdot \Delta T d z(14)
$$

The term $(1-W)^{\frac{1}{2}}$ in the left-hand side of solution (14) is expanded into a Taylor's series to give the following simplified solution,

$$
W \doteqdot \beta m^{-\alpha}
$$

where

$$
\begin{aligned}
& \alpha=(3+n) / 6 \\
& \beta=A \cdot k^{-\frac{1}{2}} \cdot(6 / \pi \rho)^{-\frac{n}{6}} \cdot K \cdot\left(\int_{0}^{z_{0}} \Delta T d z\right) \\
& =\left(0.96 \cdot \pi / L_{f}\right) \cdot[3 /(2 \pi \nu)]^{\frac{1}{2}} \cdot k^{-\frac{1}{2}} \\
& \cdot\left(6 / \pi \rho_{w}\right)^{-\frac{n}{6}} \cdot(1 / \rho)^{\frac{1}{2}} \cdot K \cdot\left(\int_{0}^{z_{0}} \Delta T d z\right) \\
& \propto(1 / \rho)^{\frac{1}{2}} \cdot\left(\int_{0}^{z_{0}} \Delta T d z\right)
\end{aligned}
$$

Equation (15) becomes the same form as Eq. (2).

Equation (16) shows that $\alpha$ depends on the exponent $n$ in the relationship between the fall velocity and the melted diameter of Eq. (12) alone but the effect of the fall velocity on the parameter $\alpha$ is small, because the value of exponent $n$ is generally smaller than 1 and $n / 6$ is relatively small compared to $1 / 2$. Therefore, the parameter $\alpha$ depends slightly on the fall velocity of the snowflake.

On the other hand, Eq. (17) shows that $\beta$ is proportional to the heat content of the air column below the melting layer $\int_{0}^{z_{0}} \Delta T d z$ and inversely proportional to the square root of the density of the ice skeleton $\rho$ besides the dependency of the fall velocity. That is to say, $\beta$ depends on the meteorological condition of the melting layer besides the physical characteristics of the snowflake such as fall velocity and the density of the ice skeleton.

In order to estimate the parameter $\alpha$, we use the relationship between the fall velocity and the melted diameter obtained by Sasyo and Matsuo (1980) i.e.

$$
V=292 D^{0.46}
$$

The parameters $\alpha$ can be rewritten by using $k=292$ and $n=0.46$ in following form

$$
\alpha=1 / 2+0.46 / 6
$$

The parameter $\alpha$ becomes 0.57 and the value agrees well with the average of $\alpha$ obtained in the field observations (0.53).

On the other hand, it is difficult to estimate $\beta$ because $\beta$ contains the density of the ice skeleton which is an unknown quantity. However, Eq. (17) indicates that the parameter $\beta$ is proportional to the heat content of the melting layer $\int_{0}^{z_{0}} \Delta T d z$ under the condition of constant density.

In order to estimate the $\beta$ vs. $\int_{0}^{z_{0}} \Delta T d z$ relationship, the heat content in the melting layer is calculated by using the aerological data of routine observations at Wajima meteorological observatory for the Ishiuchi site and the data at Tateno aerological observatory for the Hiratsuka site. Incidentally, Wajima meteorological observatory lies about $150 \mathrm{Km}$ to the north west of the Ishiuchi site and Tateno aerological observatory about $120 \mathrm{Km}$ to the north east of the Hiratsuka site. $\beta$ values are obtained from the observation data (Table 1). Figure 4 shows the $\beta$ vs. $\int_{0}^{z_{0}} \Delta T d z$ relationship. The dates of the observations are shown beside the corresponding points. Two sets (5 Jan. and 27 Feb. 1988) have considerably larger values of $\beta$ than the others.

The data are too scanty to discuss the $\beta$ vs. $\int_{0}^{z_{0}} \Delta T d z$ relationship but the figure seems to show that there are two linear relationships between $\beta$ and $\int_{0}^{z_{0}} \Delta T d z$ as shown by the dotted lines OA and OB. One of reasons for this is that there are two groups snowflakes with different density, and the linear relationship $\beta$ vs. $\int_{0}^{z_{0}} \Delta T d z$ holds separately for each group as expected from Eq. (17). However, uncertainties still exist on this point. 


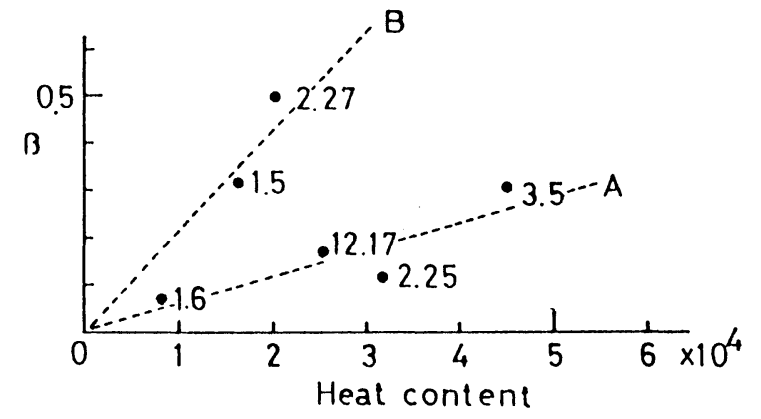

Fig. 4. Relationship between $\beta$ and the heat content obtained from radio sonde data, $\int_{0}^{z_{0}} \Delta T d z$. The dates of observations are shown beside the corresponding points.

\section{Discussion}

Snowflakes show a wide variation in their liquid water content. The major reason for this may be variety of configurations caused by aggregations and the breaking of snowflakes. On the average, the liquid water content of snowflakes increases with fall distance below the freezing level. Also, the smaller the mass of snowflake, the larger the liquid water content. Snowflakes grown by the aggregation of smaller snowflakes in a lower region of the melting layer have a liquid water content larger than those grown in an upper region of the melting layer. On the other hand, small snowflakes just formed by the breaking of large snowflakes with low liquid water content would be low in liquid water content even if the snowflake is small in mass.

In the case of graupel (25 Feb. 1988), $\alpha$ has a very large value (0.95) and $\beta$ a very small value $(0.07)$. These facts can be interpreted from Eq. (16) and (17) in terms of the faster fall velocity and larger density of graupel.

The observed $W$ vs. $m$ relationship was able to be derived by solving Eq. (4) that governs the melting of snowflakes. $\alpha$ and $\beta$ are also driven by Eqs. (16) and (17) respectively.

In order to estimate the $\beta$ vs. $\int_{0}^{z_{0}} \Delta T d z$ relationship, the heat content at the Ishiuchi site is substituted for that at the Wajima meteorological observatory and the heat content at the Hiratsuka site is substituted for that at the Tateno aerological observatory. As shown in Table 1, the observed freezing levels are at several hundreds meters or less, that is to say, the melting layers are very thin with their bottoms in contact with the ground surface. Therefore, the vertical temperature profile in the melting layer $\Delta T(z)$ may be affected considerably by topographic conditions near the observation site.

For this reason, to predict $\beta$ from the heat content simultaneous observations should be carried out for the liquid water content and the vertical temperature profile in the melting layer at the same location.

\section{Conclusion}

A new instrument has been developed to measure the liquid water content of melting snowflakes and the new instrument was utilized for the field observation of sleet.

The results are summarized as follows.

(1) Snowflakes show a wide variety of liquid water content even if the masses are the same.

(2) The relationship between the liquid water content and the mass is approximated by the following equation.

$$
\log W=-\alpha \log m+\log \beta
$$

where $m$ is the mass of snowflake $(\mathrm{mg})$ and $W$ the average liquid water content of snowflakes with mass of $m$. The parameter $\alpha$ ranges from 0.27 to 0.95 ( 0.53 on average) and $\beta$ from 0.07 to 0.51 ( 0.25 on average).

(3) Theoretical treatment of $\alpha$ and $\beta$ shows that $\alpha$ is a function of the exponent $n$ in the relationship between the fall velocity and the melted diameter as shown by Eq. (16) and parameter $\beta$ is proportional to the heat content in the melting layer $\int_{0}^{z_{0}} \Delta T d z$ and inversely proportional to the square root of the density of the ice skeleton $\rho$, not to mention the fall velocity.

\section{Acknowledgements}

The authors would like to thank Dr. M. Yasui and Mr. T. Naito of the Tokyo Electric Power Company for providing every convenience possible for the observations. We also would like to thank Mr. N. Suga (President) of the Suga Weathering Technical Fundation and the Suga Weathering Test Instrument Company Limited and Mr. T. Kimura (head of Research and Development) of the Suga Weathering Test Instrument Company Limited. We are much indebted to Dr. M. Kano for his valuable comments. This work was carried out in joint research with the Tokyo Electric Power Co.

\section{References}

Langleben, M.P., 1954: The terminal velocity of snowflakes. Quart. J. Roy. Meteor. Soc., 80, 178181.

Matsuo, T. and Y. Sasyo, 1981: Melting of snowflakes below freezing level in the atmosphere. J. Meteor. Soc. Japan, 59, No. 1, 10-24.

Nakamura, T., 1960: On the method of measuring the liquid water content of falling snowflakes (in Japanese). Seppyo, 22, 145-146.

Sasyo, Y. and T. Matsuo, 1980: On the statistical investigation of fall velocity of the snowflake. Pap. Meteor. Geophys., 31, 61-79.

Sasyo, Y., T. Mori, O. Onozaki, T. Saito and K. Tsutsui, 1990: On the accuracy of the method for measuring 
the mass of precipitation particles by using a filter paper (in Japanese). Tenki, 37, 61-66.

Yuge, T., 1960: Experiments on heat transfer from spheres including combined natural and forced convection. J. Heat Transfer, 82, 214-220.

\section{雪片の含水率の測定に就いて \\ 佐粧純男・森 太郎・小野崎統・斎藤貴志}

(スガ試験機株式会社開発部)

ろ紙による雪片の含水率測定法 (中村、1960) を自動化した含水率計を試作し、野外観測を行った。その 結果

(1) 含水率は、同じ質量の雪片同志の間でも大きなばらつをを示した。

(2) 同じ質量を持つ雪片の平均含水率 $(\mathrm{W})$ と質量 $(\mathrm{m})$ との間には、

$$
\log W=-\alpha \log m+\log \beta
$$

の近似式が成り立った。こてで、 $\alpha$ と $\beta$ は質量に関係のない定数で、 $\alpha$ の值は 0.27 から 0.95 の間にあり、平 均は 0.53 また、 $\beta$ は 0.07 から 0.51 、平均 0.25 であった。

(3) 定数 $\alpha 、 \beta$ の物理的意味を知る為に、雪片の融解方程式を解いて、(2) 式と同じ含水率と質量の関係を得 た。その結果 $\alpha$ は落下速度だけに関係しているのに対して 密度、融解層内で周りの空気から雪片に輸送される熱量などに関係しているととがわかった。 